\title{
Porous Rh/BINAP polymers as efficient heterogeneous catalysts for asymmetric hydroformylation of styrene: Enhanced enantioselectivity realized by flexible chiral nanopockets
}

\author{
Tao Wang a,b, Wenlong Wang a, Yuan Lyu a,\#, Kai Xiong c, Cunyao Li a,b, Hao Zhang d, \\ Zhuangping Zhan c, Zheng Jiang d, Yunjie Ding a,* \\ a Dalian National Laboratory for Clean Energy, Dalian Institute of Chemical Physics, Chinese Academy of Sciences, Dalian 116023, Liaoning, China \\ b University of Chinese Academy of Sciences, Beijing 100049, China \\ c Department of Chemistry, Xiamen University, Xiamen 361005, Fujian, China \\ d Shanghai Synchrotron Radiation Facility, Shanghai Institute of Applied Physics, Chinese Academy of Sciences, Shanghai 201204, China
}

\section{A R T I C L E I N F}

\section{Article history:}

Received 15 December 2016

Published 5 April 2017

\section{Keywords:}

Porous organic polymer

Heterogeneous catalysis

Asymmetric hydroformylation

Chiral nanopocket
Accepted 15 January 2017

Enhanced enatioselectivity

\begin{abstract}
A B S T R A C T
A new chiral monomer, (S)-5,5'-divinyl-BINAP, was successfully synthesized and embedded into two different porous organic polymers (Poly-1 and Poly-2). After loading a Rh species, the catalysts were applied for the heterogeneous asymmetric hydroformylation of styrene. Compared with the homogeneous BINAP analogue, the enantioselectivity of Rh/Poly-1 catalyst was drastically increased by approximately $70 \%$. The improved enantioselectivity of the porous Rh/BINAP polymers was attributed to the presence of flexible chiral nanopockets resulting from the increased bulk of the R groups near the catalytic center.
\end{abstract}

(C) 2017, Dalian Institute of Chemical Physics, Chinese Academy of Sciences. Published by Elsevier B.V. All rights reserved.

\section{Introduction}

Asymmetric hydroformylation is one of the most versatile methods for the synthesis of enantiomerically pure compounds such as optically active aldehydes, $\alpha$-amino acids and alcohols. Although it has been researched for more than 40 years, asymmetric hydroformylation with good enantioselectivity, chemoselectivity and regioselectivity is still a challenge in the field of catalysis and fine chemical synthesis [1].

So far, Rh catalysts associated to chiral phosphine-phosphite ligands or diphosphite ligands are the most studied systems in asymmetric hydroformylation, and some satisfactory results have been reported [2-5]. For example, Nozaki et al. [6] developed the chiral phosphine-phosphite ligand $(R, S)$ BINAPHOS; hydroformylation of styrene with high enantioselectivity was achieved (up to $94 \% e e$, iso/normal $=7.3$ ) by using Rh complexes of this new ligand. However, although diphosphine ligands show excellent catalytic activities in asymmetric hydrogenation, they always lead to disappointing results in asymmetric hydroformylation of styrene $[7,8]$. An $e e$ value of $60 \%$ has been obtained in a Rh-diphosphine system by using a chiral BDPP ligand [9]. Other diphosphines such as DIOP, TREDIP and CHRAPHOS give low enantioselectivities of less than $30 \%$ [8-11]. BINAP ligand, which is unambiguously one of

\footnotetext{
* Corresponding author. Tel: +86-411-84379143; Fax: +86-411-84379143; E-mail: dyj@dicp.ac.cn

\# Corresponding author. Tel: +86-411-84379601; Fax: +86-411-84379143; E-mail: luyuan@dicp.ac.cn

This work was supported by the Strategic priority Research Program of the Chinese Academy of Sciences (XDB17020400).

DOI: 10.1016/S1872-2067(17)62790-6| http://www.sciencedirect.com/science/journal/18722067 | Chin. J. Catal., Vol. 38, No. 4, April 2017
} 


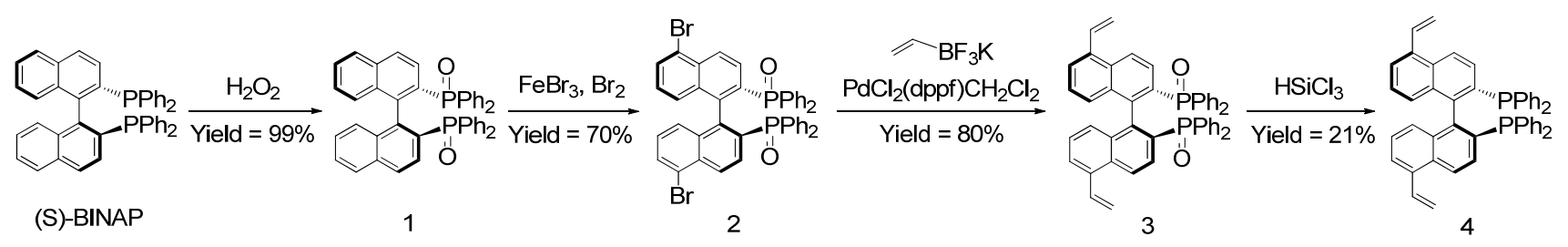

Scheme 1. Synthesis of 5,5'-divinyl-BINAP.

the most prominent chiral ligands for asymmetric catalysis [12-14], only exhibits an ee value of $25 \%$ when combined with Rh species for the asymmetric hydroformylation of styrene [9]. Many modified structures of BINAP have been prepared to increase the efficiency or enantioselectivity of asymmetric hydrogenation [15]. Lin et al. [16] developed a family of 4,4'-substituted BINAP derivatives for asymmetric hydrogenation of ethyl benzoylacetate. The Ru catalysts based on bulky substituents of BINAP, such as trimethylsilane, diphenylmethanol and 1-cyclopentanol, provided ee values of more than $99 \%$. When using relatively small substituents, such as methyl and phenyl, the catalysts provided ee values of less than $87 \%$. Remarkably, the enantioselectivity was dramatically enhanced when bulky groups were introduced at the 4,4'-positions of BINAP. The reason could be explained by the significant repulsive interactions between the bulky substituents of BINAP and the phenyl group of the substrate, which results in destabilization of the disfavored transition state, and thus, a dramatic enhancement of the enantioselectivity. These ligands with a "chiral pocket"like design have been reported in recent years [17-20]. However, BINAP-based ligands have rarely been reported for hydroformylation reactions owing to their relatively low enantioselectivity. Considering that BINAP is one of the most important chiral ligands, can be produced at an industrial scale and has extensive applications in asymmetric catalysis, modified BINAP-related catalysts for hydroformylation reactions deserve further investigations.

The disadvantages of homogeneous catalysis, such as the waste of expensive transition metal complexes and contamination of products, drove us to explore more practical heterogeneous systems [21-24]. The immobilization of organometallic complexes onto highly porous solids is still an excellent strategy for combining the advantages of homogeneous and heterogeneous catalysts $[25,26]$. Among various porous supporting materials, porous organic polymers, an emerging class of porous materials, could be a promising candidate because of their high surface areas, advanced hierarchical pore structures and outstanding stabilities $[27,28]$. Recently, porous polymers with excellent swelling properties were prepared through the polymerization of vinyl-functionalized monomers under solvothermal conditions [29,30]. The swollen polymers can be characterized as a solution to a certain degree, although they are elastic solids rather than liquids; this liquid-like nature endows the polymers with surprisingly high flexibility. Even more important, it has been well recognized that the flexibility of the active sites in solid catalysts plays a very important role in the improvement of the catalytic performance.

Previously, our group reported a series of highly efficient heterogeneous hydroformylation catalysts prepared by the copolymerization of vinyl-functionalized $\mathrm{PPh}_{3}$ with vinyl-functionalized biphephos ligand $[31,32]$. More importantly, Xiao et al. [33] synthesized chiral porous cross-linked polymers (PCP-BINAP) under solvothermal conditions. PCP-BINAPO was first obtained through the copolymerization of divinylbenzene and 5,5'-diacryloylamino BINAP dioxide. Then, PCP-BINAP was synthesized by the reduction of PCP-BINAPO with $\mathrm{HSiCl}_{3}$. The prepared Ru/PCP-BINAP catalyst exhibited high activity, excellent enantioselectivity, and extraordinary recyclability in asymmetric hydrogenation of $\beta$-keto esters.

Inspired by Xiao's work, in this paper we also report a vinyl-modified BINAP, (S)-5,5'-divinyl-BINAP, and its corresponding porous organic polymers afforded by the copolymerization with divinyl benzene and 1,3,5-tri(4-vinylphenyl)benzene (Scheme 1). Linear ethylene glycol dimethacrylate monomer was also copolymerized with divinyl-modified BINAP; however, a nonporous material was obtained and this material was introduced as a negative control. The BINAP ligand was not only simply incorporated into the polymers, but can also be considered as modified by bulky blocks from other co-monomers or BINAP itself. Thus, numerous highly flexible nanoporous chiral pockets were present in the polymer materials (Scheme 2). After loading with Rh species, the nanoporous chiral-pockets-based BINAP polymers should be very favorable for the improvement of the enantioselectivity of the asymmetric hydroformylation of styrene. To demonstrate the "proof-ofconcept", in this contribution, two porous polymer-supported $\mathrm{Rh} / \mathrm{BINAP}$ catalysts were designed and synthesized and their
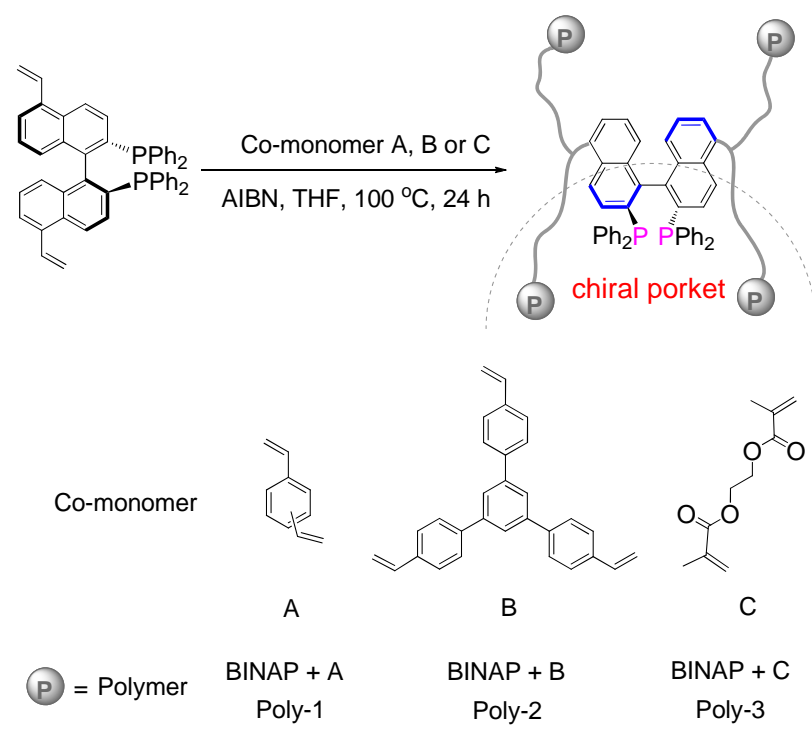

Scheme 2. Synthesis and structures of Poly-1, Poly-2, and Poly-3. 
catalytic performance and recyclability were investigated for the heterogeneous asymmetric hydroformylation of styrene.

\section{Experimental}

\subsection{Materials}

All solvents were analytical grade and were purified by distillation under Ar atmosphere before use. Unless otherwise noted, all manipulations were carried out under an Ar atmosphere either in a glove-box or using standard Schlenk techniques.

\subsection{Synthesis of (S)-5,5'-divinyl-BINAP}

\subsubsection{Synthesis of compound 1, (S)-BINAP dioxide}

$(S)$-BINAP (3 mmol, $1.87 \mathrm{~g}$ ) was dissolved in dichloromethane (DCM, $60 \mathrm{~mL}$ ), followed by dropwise addition of $\mathrm{H}_{2} \mathrm{O}_{2}$ (18.32 mmol, $6.06 \mathrm{~mL}$ ). The reaction was monitored by thin-layer chromatography (TLC). After stirring for $30 \mathrm{~min}$ at room temperature, the solution was extracted with water (30 $\mathrm{mL}$ ). The organic phase was washed with $10 \% \mathrm{NaHSO}_{3}$ aqueous solution $(50 \mathrm{~mL})$ and dried over $\mathrm{Na}_{2} \mathrm{SO}_{4}$. The solvent was removed under vacuum and (S)-BINAPO was obtained as a white solid (1.95 g, 99\% yield).

\subsubsection{Synthesis of compound 2, (S)-5,5'-diBr-BINAPO}

$(S)$-BINAPO (1.0 mmol, $0.65 \mathrm{~g}$ ) was dissolved in dichloroethane (DCE, $15 \mathrm{~mL}$ ), followed by the addition of $\mathrm{FeBr}_{3}(2.2$ mmol, $0.65 \mathrm{~g}$ ) and liquid bromine ( $2.2 \mathrm{mmol}, 0.35 \mathrm{~g})$. After refluxing for $12 \mathrm{~h}$, the solution was washed with $10 \% \mathrm{NaHSO}_{3}$ aqueous solution, saturated brine and saturated sodium bicarbonate aqueous solution, and dried over $\mathrm{Na}_{2} \mathrm{SO}_{4}$. After refluxing for $12 \mathrm{~h},(S)-5,5^{\prime}$-diBr-BINAPO was obtained.

\subsubsection{Synthesis of compound 3, (S)-5,5'-divinyl-BINAPO}

$(S)$-5,5'-diBr-BINAPO (1.0 mmol, $0.82 \mathrm{~g}$ ), potassium vinyltrifluoroborate (2.4 mmol, $0.32 \mathrm{~g}$ ) and $\mathrm{PdCl}_{2}(\mathrm{dppf}) \mathrm{CH}_{2} \mathrm{Cl}_{2}(0.08$ mmol, $0.058 \mathrm{~g}$ ) were placed in a three-necked flask. $n$-PrOH (10 $\mathrm{mL})$ and triethylamine $(2.0 \mathrm{mmol}, 0.20 \mathrm{~g})$ were added to the flask. The reaction was monitored by TLC. After refluxing for 3 $h$, the solvent was removed under vacuum. The precipitate was passed through a silica gel column and dried under vacuum to give (S)-5,5'-divinyl-BINAPO as a white solid $(0.565 \mathrm{~g}, 80 \%$ yield).

\subsubsection{Synthesis of compound 4, (S)-5,5'-divinyl-BINAP}

(S)-5,5'-divinyl-BINAPO (1.0 mmol, $0.70 \mathrm{~g})$, trichlorosilane ( $3.0 \mathrm{mmol}, 0.41 \mathrm{~g}$ ) and phenylsilane $(3.0 \mathrm{mmol}, 0.32 \mathrm{~g}$ ) were placed in a three-necked flask containing toluene $(10 \mathrm{~mL})$. The reaction was monitored by TLC. After refluxing for $3 \mathrm{~h}$, the solvent was cooled to $0{ }^{\circ} \mathrm{C}$ followed by slow addition of $\mathrm{NaOH}$ aqueous solution. Then the solution was extracted with water, and dried over $\mathrm{Na}_{2} \mathrm{SO}_{4}$. The solvent was removed under vacuum. The precipitate was passed through a silica gel column and dried under vacuum to give $(S)-5,5^{\prime}$-divinyl-BINAP as a white solid (0.15 g, 21\% yield). ${ }^{1} \mathrm{H}$ NMR (400 MHz, $\left.\mathrm{CDCl}_{3}\right) \delta 5.47$ (dd, $\left.1 \mathrm{H}, J_{1}=10.9 \mathrm{~Hz}, J_{2}=1.6 \mathrm{~Hz}\right), 5.76\left(\mathrm{dd}, 1 \mathrm{H}, J_{1}=17.3 \mathrm{~Hz}, J_{2}=1.6\right.$ $\mathrm{Hz}), 6.79(\mathrm{~d}, 1 \mathrm{H}, J=8.4 \mathrm{~Hz}), 6.85-6.90(\mathrm{~m}, 1 \mathrm{H}), 7.05-7.17(\mathrm{~m}$, $10 \mathrm{H}), 7.45-7.51(\mathrm{~m}, 3 \mathrm{H}), 8.17(\mathrm{~d}, 1 \mathrm{H}, J=8.8 \mathrm{~Hz}) ;{ }^{13} \mathrm{C}$ NMR $(100$ $\left.\mathrm{MHz}, \mathrm{CDCl}_{3}\right) \delta 117.2,123.9,124.4,125.5,127.6,127.7,128.0$, $128.4,130.7,130.9,132.8,132.9,133.0,133.5,134.1,134.2$, 134.3, 134.5, 135.4; ${ }^{31} \mathrm{P}$ NMR (161 $\left.\mathrm{MHz}, \mathrm{CDCl}_{3}\right)-15.7 \mathrm{~Hz}$; HRMS(ESI): $m / z$ calc. for $\mathrm{C}_{48} \mathrm{H}_{44} \mathrm{O}_{6} \mathrm{P}_{2}[\mathrm{M}+\mathrm{H}]^{+}: 675.2370$, found: 675.2373.

\subsection{Synthesis of polymers}

These polymers were prepared through a free-radical polymerization of vinyl-functionalized BINAP ligand and other co-monomers in $\mathrm{THF}$ at $100{ }^{\circ} \mathrm{C}$. In an autoclave, $0.30 \mathrm{~g}$ of (S)-5,5'-divinyl-BINAP and $0.60 \mathrm{~g}$ of divinyl benzene (DVB) were dissolved in $9 \mathrm{~mL}$ of tetrahydrofuran (THF), followed by the addition of $23 \mathrm{mg}$ of 2,2'-azoisobutyronitrile (AIBN). The mixture was first stirred for $10 \mathrm{~min}$ at the room temperature and then heated at $100{ }^{\circ} \mathrm{C}$ for $24 \mathrm{~h}$. The solvent was removed under vacuum at $65{ }^{\circ} \mathrm{C}$ and a white solid was obtained, which was denoted as Poly-1.

Poly-2 was obtained using the same synthesis method but using $0.60 \mathrm{~g}$ of 1,3,5-tri(4-vinylphenyl)benzene instead of 0.60 g DVB.

Poly-3 was obtained using the same synthesis method but using $0.91 \mathrm{~g}$ of ethylene glycol dimethacrylate instead of $0.60 \mathrm{~g}$ DVB.

\subsection{Characterization}

Nitrogen isotherms at $-196{ }^{\circ} \mathrm{C}$ were measured using Quantachrome Autosorb-1. The samples were outgassed at 120 ${ }^{\circ} \mathrm{C}$ for $10 \mathrm{~h}$. The pore size distributions were calculated using density functional theory (DFT) method.

Thermogravimetric analysis (TGA) was measured using NETZSCH STA 449F3, and the samples were heated from 40 to $1000^{\circ} \mathrm{C}$ at a rate of $10^{\circ} \mathrm{C} / \mathrm{min}$ under air.

Transmission electron microscopy (TEM) images were taken on a JEM-2100 with an accelerating voltage of $200 \mathrm{kV}$. The morphologies of the polymers were investigated on a JSM-7800F scanning electron microscope (SEM).

Solid-state NMR spectra were obtained on a VARIAN infinity plus 400 spectrometer. The ${ }^{31 P}$ MAS NMR spectra were recorded with a $2.5 \mathrm{~mm}$ probe at a frequency of $161.8 \mathrm{MHz}$ under a magic angle spinning rate of $10 \mathrm{kHz}$ and a delay of $3 \mathrm{~s}$. The chemical shifts were referenced to $85 \% \mathrm{H}_{3} \mathrm{PO}_{4}{ }^{13} \mathrm{C}$ MAS NMR spectra were recorded under a magic angle spinning rate of 6 $\mathrm{kHz}$.

The K-edge X-ray absorption fine structure (EXAFS) spectra of Rh were obtained at the BL14W1 beamline of SSRF, SINAP (Shanghai, China) with the use of a Si(311) crystal monochromator. The storage ring was operated at $3.5 \mathrm{GeV}$ with injection currents of $200 \mathrm{~mA}$. The data of the samples were recorded in fluorescence mode. The XAFS data were analyzed by using the Demeter software package. Fourier transformation of the EXAFS data was applied to the $\mathrm{k}^{3}$-weighted functions. The theoretical scattering amplitude and phase-shift functions of all 
the paths for fitting the EXAFS data were calculated by FEFF6 code.

\subsection{Catalytic process}

\subsubsection{Typical procedure for asymmetric hydroformylation}

As a typical run, a mixture of Poly-1 (19 mg, $0.0096 \mathrm{mmol} \mathrm{P})$ and $\mathrm{Rh}(\mathrm{CO})_{2}$ (acae) $(0.25 \mathrm{mg}, 0.00096 \mathrm{mmol})$ in toluene $(2 \mathrm{~mL})$ was heated to $100{ }^{\circ} \mathrm{C}$ for $10 \mathrm{~h}$ under $\mathrm{Ar}$, then styrene was added. After purging with syngas $\left(\mathrm{H}_{2} / \mathrm{CO}=1: 1\right) 4$ times, the pressure was adjusted to the desired value and the reaction mixture was stirred at $80^{\circ} \mathrm{C}$ for $24 \mathrm{~h}$. After the reaction, the catalyst was separated by centrifugation, and the product (yield for aldehydes and regioselectivity for 2-phenylpropionaldehyde) was analyzed by gas chromatography (Agilent 7890B gas chromatography equipped with a flame ionization detector and a Cyclodex-B capillary column). A sample of the reaction mixture was treated with Jones reagent to oxidize the aldehydes to carboxylic acids, which were used to determine the enantiomeric excess $(e e)$ by GC.

\subsubsection{Typical procedure for preparing racemic products}

$\mathrm{PPh}_{3}$ (30.0 mg, $0.114 \mathrm{mmol} \mathrm{P),} \mathrm{Rh}(\mathrm{CO})_{2}$ (acae) (3.0 mg, $0.0114 \mathrm{mmol})$, 4-chlorostyrene (1.5 g, $9.71 \mathrm{mmol})$ and toluene (2 mL) were mixed in a $25-\mathrm{mL}$ autoclave. After purging with syngas $\left(\mathrm{H}_{2} / \mathrm{CO}=1: 1\right) 4$ times, the pressure was adjusted to 3.0
MPa and stirred at $80^{\circ} \mathrm{C}$ for $12 \mathrm{~h}$. The reaction solution was collected and passed through a silica-gel column with petroleum ether/ethyl acetate $(5: 1 \mathrm{v} / \mathrm{v})$. The racemic product of the branched aldehyde was confirmed by GC-MS (Agilent 7890-5975C). An aliquot of pure racemic branched aldehyde was further treated with Jones reagent to oxidize the aldehydes to carboxylic acids, which were used to determine their retention times.

\section{Results and discussion}

\subsection{Characterization results}

${ }^{13} \mathrm{C}$ magic angle spinning (MAS) NMR spectra were used to characterize the polymers (Fig. 1(a)). All the polymers showed broad resonance peaks from 120 to $150 \mathrm{ppm}$, which were assigned to the aromatic carbons. The signals from 20 to $55 \mathrm{ppm}$ were attributed to the methylene linker. The structure information of Rh/Poly-1 remains the same as that of Poly- 1 in the ${ }^{13} \mathrm{C}$ MAS NMR. The position of the spinning sidebands in $\mathrm{Rh} /$ Poly-1 was different from that of Poly-1. This is because the ${ }^{13} \mathrm{C}$ MAS NMR spectra of Rh/Poly-1 was recorded under a magic angle spinning rate of $9 \mathrm{kHz}$, whereas the other materials were recorded under a magic angle spinning rate of $6 \mathrm{kHz}$. Additionally, the 31P MAS NMR spectrum of Poly-1 showed one main signal at -14.5 ppm (Fig. 1(b)), which was at the same
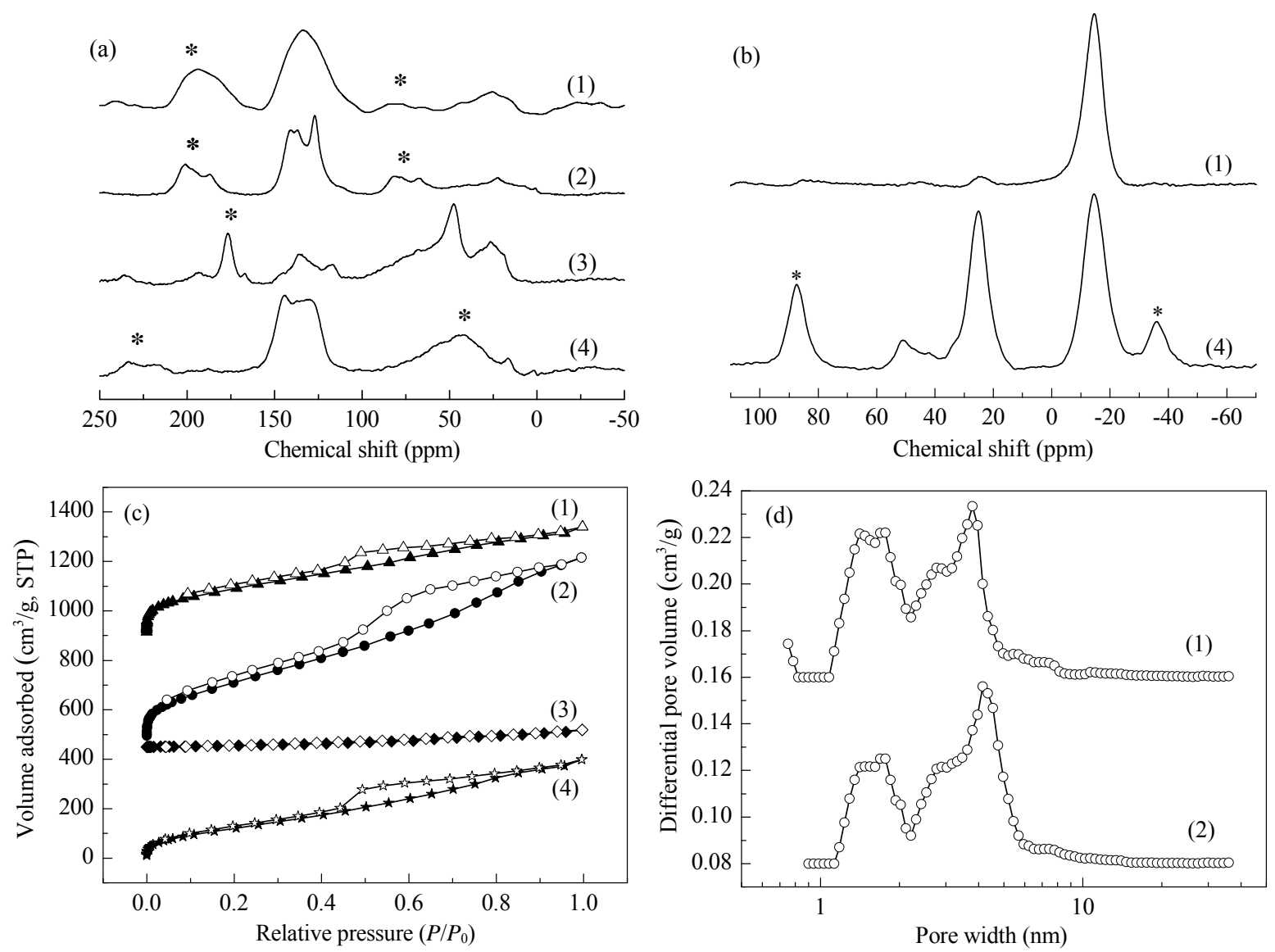

Fig. 1. (a) ${ }^{13} \mathrm{C}$ CP/MAS NMR, (b) ${ }^{31} \mathrm{P}$ MAS NMR, (c) $\mathrm{N}_{2}$ isotherms and (d) pore size distribution of (1) Poly-1, (2) Poly-2, (3) Poly-3 and (4) Rh/Poly-1. Asterisks denote spinning sidebands. 
position as the ligand. These observations indicated that the BINAP moieties were stable during the solvothermal polymerization process. After loading the Rh species, the ${ }^{31}$ P MAS NMR spectrum of Rh/Poly-1 exhibited a relatively high resonance signal at $25.1 \mathrm{ppm}$ owing to phosphorous oxide. A resonance peak at 52.0 ppm was also present, which was assigned to the unprotected phosphine coordinated with the Rh species [34].

The pore properties of the materials were analyzed by $\mathrm{N}_{2}$ physisorption isotherms (Fig. 1(c)). The curves of Poly-1 and Poly-2 collected at $-196^{\circ} \mathrm{C}$ exhibited combined features of type I and type IV hysteresis with an obviously steep step in the $P / P_{0}$ $<0.01$ region and hysteresis loops in the $0.60<P / P_{0}<0.95$ region, which suggests that micro- and mesopores were present in the polymer. These data were confirmed by the pore size distribution curves calculated by nonlocal density functional theory method (NLDFT); the pore sizes of two types of pores were distributed at approximately $0.5-1.5$ and 2.5-10 nm, respectively (Fig. 1(d)). The Brunauer-Emmet-Teller surface areas of Poly-1 and Poly-2 were estimated to be 697 and $997 \mathrm{~m}^{2} / \mathrm{g}$, respectively, and the pore volumes were calculated to be 0.68 and $1.19 \mathrm{~cm}^{3} / \mathrm{g}$, respectively. Rh/Poly-1 exhibited a lower surface area and pore volume $\left(490 \mathrm{~m}^{2} / \mathrm{g}, 0.56 \mathrm{~cm}^{3} / \mathrm{g}\right.$, respectively) than Poly-1, because that part of the material space was occupied after loading with Rh species. Compared with the co-monomers divinyl benzene and 1,3,5-tri(4-vinylphenyl)benzene, which are rigid bulky blocks, the ethylene glycol dimethacrylate has longer carbon chains with a linear structure and afforded a nonporous Poly-3. Another reason to explain the condensed structure of Poly- 3 is the hydrogen bonding between the hydrogen atoms and the carboxyl groups.

\subsection{Catalytic activity}

The Rh-based catalysts were afforded by impregnating the polymers with $\mathrm{Rh}(\mathrm{CO})_{2}$ (acac) dissolved in toluene. Styrene was chosen as a substrate to detect the asymmetric hydroformylation activities of the polymeric catalysts. Although the catalysts were insoluble, they were prone to swelling in many solvents. Therefore, we initially chose three solvents that have been used most frequently in asymmetric hydroformylation to test the catalytic performance of Rh/Poly-1 (Table 1). The results showed that the three solvents gave similar yield for aldehydes, but provided different regioselectivities and enantioselectivi-

\section{Table 1}

The performance of Rh/Poly-1 for hydroformylation in various solvents.

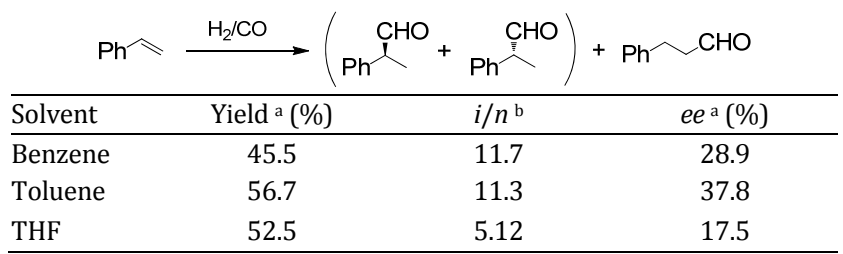

Reaction conditions: $2 \mathrm{~mL}$ solvents, $\mathrm{H}_{2} / \mathrm{CO}=1: 1(1 \mathrm{MPa}), 0.00096$ mmol Rh with the molar ratio of $\mathrm{P} / \mathrm{Rh}=10, \mathrm{~S} / \mathrm{C}=2000,80^{\circ} \mathrm{C}, 24 \mathrm{~h}$.

a Determined by GC on a Cyclodex-B capillary column.

${ }^{\mathrm{b}}$ Molar ratio of branched to linear aldehyde in the products, determined by GC.
Table 2

The optimization of parameters for hydroformylation reaction by Rh/Poly-1.

\begin{tabular}{lccccc}
\hline Entry & Temp. $\left({ }^{\circ} \mathrm{C}\right)$ & $P(\mathrm{MPa})$ & Yield $^{\mathrm{a}}(\%)$ & \multicolumn{1}{c}{$i / n$} & $e e^{\mathrm{a}}(\%)$ \\
\hline 1 & 60 & 1 & 7.6 & 14.8 & 56.3 \\
2 & 70 & 1 & 23.1 & 12.4 & 30.6 \\
3 & 80 & 1 & 56.7 & 11.3 & 37.8 \\
4 & 90 & 1 & 74.1 & 10.0 & 28.3 \\
5 & 100 & 1 & 96.9 & 9.1 & 20.3 \\
6 & 110 & 1 & 93.5 & 6.3 & 25.3 \\
7 & 80 & 0.2 & 93.5 & 8.5 & 58.9 \\
8 & 80 & 0.5 & 68.3 & 11.2 & 42.0 \\
9 & 80 & 1.5 & 34.4 & 11.8 & 38.7 \\
10 & 80 & 3 & 12.1 & 12.0 & 35.4 \\
11 & 80 & 4 & 7.1 & 12.3 & 31.6 \\
\hline
\end{tabular}

Reaction conditions: $2 \mathrm{~mL}$ toluene, $\mathrm{H}_{2} / \mathrm{CO}=1: 1,0.00096 \mathrm{mmol} \mathrm{Rh}$ with the molar ratio of $\mathrm{P} / \mathrm{Rh}=10, \mathrm{~S} / \mathrm{C}=2000,24 \mathrm{~h}$.

a Determined by GC on a Cyclodex-B capillary column.

ties; the highest enantioselectivity (37.8\%) was afforded by $\mathrm{Rh} / \mathrm{Poly}-1$ using toluene as a solvent. Toluene was selected as a solvent to investigate the effect of temperature on the reaction in the range of $60-110{ }^{\circ} \mathrm{C}$ (Table 2, entries 1-6). When the temperature increased, the yield significantly increased from $7.6 \%$ to $93.5 \%$. In sharp contrast, the regioselectivity and enantioselectivity both decreased with the increase in the temperature. As a result, $80^{\circ} \mathrm{C}$ was selected as an appropriate temperature for further investigation. The impact of the pressure of $\mathrm{H}_{2} / \mathrm{CO}$ was investigated (Table 2, entries 7-11). When the reaction pressure was decreased from 4.0 to $0.2 \mathrm{MPa}$, the yield increased from $7.1 \%$ to $93.5 \%$, although the regioselectivity decreased from $12.3 \%$ to $8.5 \%$. An unexpectedly high enantioselectivity (58.9\%) was achieved when the reaction was performed near atmospheric pressure (0.2 MPa).

The catalytic performance of the three catalysts (Rh/Poly-1, $\mathrm{Rh} /$ Poly-2 and Rh/Poly-3) was examined under a pressure of $0.2 \mathrm{MPa}$ at $80^{\circ} \mathrm{C}$ for $24 \mathrm{~h}$ (Table 3, entries 1-3). These catalysts exhibited similar yields (92\%-94\%), whereas Rh/Poly-1 showed the best regioselectivity (8.5\%) and enantioselectivity (58.9\%). The results showed that the pore structures had little effect on the yields, but had a clear effect on the regioselectivity and enantioselectivity. In the swollen state, the backbones of the polymer-supported catalysts were flexible and freely mov-

Table 3

Asymmetric hydroformylation of styrene by different catalysts.

\begin{tabular}{|c|c|c|c|c|c|}
\hline Entry & Catalyst & $\mathrm{R}$ & 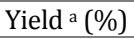 & $i / n$ & $e e^{\mathrm{a}}(\%)$ \\
\hline 1 & Rh/Ploy-1 & $\mathrm{H}$ & 93.5 & 8.5 & 58.9 \\
\hline 2 & Rh/Ploy-2 & $\mathrm{H}$ & 94.6 & 8.0 & 45.1 \\
\hline 3 & Rh/Ploy-3 & $\mathrm{H}$ & 92.2 & 6.8 & 30.7 \\
\hline 4 & Rh-BINAP b & $\mathrm{H}$ & 94.9 & 8.1 & 35.3 \\
\hline 5 & Rh/Ploy-1 & $\mathrm{Cl}$ & 98.4 & 11.9 & 21.3 \\
\hline 6 & Rh/Ploy-1 & $\mathrm{Br}$ & 88.4 & 12.6 & 36.0 \\
\hline 7 & Rh/Ploy-1 & $\mathrm{OCH}_{3}$ & 58.5 & 8.1 & 50.7 \\
\hline
\end{tabular}

Reaction conditions: $2 \mathrm{~mL}$ toluene, $\mathrm{H}_{2} / \mathrm{CO}=1: 1(0.2 \mathrm{MPa}), 0.00096$ $\mathrm{mmol} \mathrm{Rh}$ with the molar ratio of $\mathrm{P} / \mathrm{Rh}=10, \mathrm{~S} / \mathrm{C}=2000,24 \mathrm{~h}$.

a Determined by GC on a Cyclodex-B capillary column.

${ }^{\mathrm{b}}$ Homogeneous catalyst of Rh-BINAP system with $\mathrm{P} / \mathrm{Rh}=10$. 
able. Therefore, the substrate could obtain rapid access to the active sites of the heterogeneous catalysts. Meanwhile, the rigid and bulky blocks around the BINAP, such as divinyl benzene and 1,3,5-tri(4-vinylphenyl)benzene, fabricated irregular and steric pore structures, which could be favorable for the formation of chiral pockets. Efficient asymmetric hydroformylations were conducted when the substrate was coordinated with $\mathrm{Rh}$ species in the chiral pockets, and as anticipated, high enantioselectivities were obtained. The Rh/Poly-1 and Rh/Poly-2 catalysts both exhibited higher enantioselectivity than the homogeneous system. However, Rh/Poly-3, which contained long carbon chain links (ethylene glycol dimethacrylate) and showed properties of a nonporous bulk material (no chiral pocket existed), only exhibited an enantioselectivity of $30.7 \%$ and a low regioselectivity of $6.8 \%$. Rh/Poly-1 was also used to catalyze 4-substituted styrene derivatives (Table 3, entries 5-7). The presence of substrates containing electron-withdrawing groups, such as $\mathrm{Cl}$ and $\mathrm{Br}$, seemed to decrease the ee values, although they gave good conversion results. The Rh/Poly-1 gave a high ee value of $50.7 \%$ when 4-methoxystyrene was used as a substrate.

Considering the catalyst stability and reusability were of primary interests in heterogeneous catalysis, we investigated the possibility of recycling Rh/Poly-1 (Fig. 2). When the reaction was finished, the catalyst was separated by centrifugation, washed with toluene (performed under nitrogen atmosphere) and then the catalyst was used directly for the next round reaction. The catalyst was reused seven times without significant loss of activity and enantioselectivity. The fluctuation of the product yield and $e e$ values was ascribed to the reaction pressure of $\mathrm{H}_{2} / \mathrm{CO}$. We previously showed that the reaction pressure had a significant influence on the activity and enantioselectivity. Meanwhile, the yield of the product was in the level of middle when the reaction time of the recycling test was $10 \mathrm{~h}$. The initial reaction pressure was only $0.2 \mathrm{MPa}$; therefore, small changes in the pressure during the reaction would have a certain impact on the reaction results. The excellent stability of the catalyst could be ascribed to the covalently linked methylene groups, which firmly tied the chiral BINAP ligand.

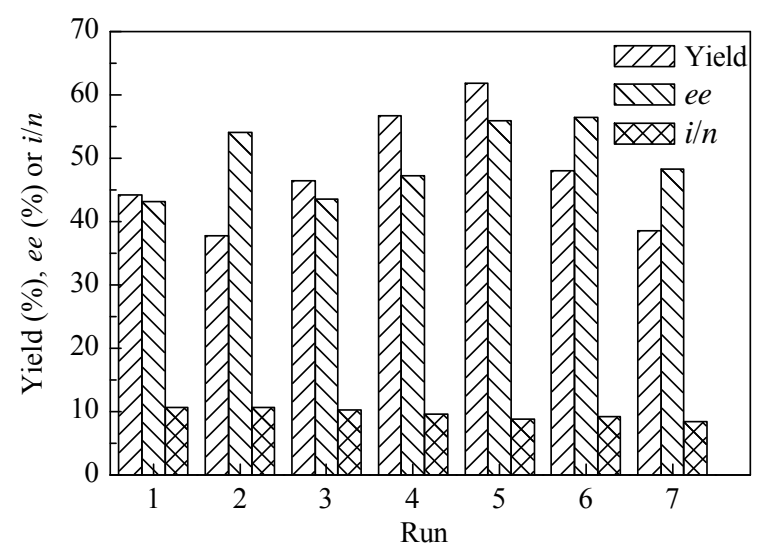

Fig. 2. Recycling studies for the asymmetric hydroformylation of styrene by $\mathrm{Rh} / \mathrm{Poly}-1$. Reaction conditions: $2 \mathrm{~mL}$ toluene, $\mathrm{H}_{2} / \mathrm{CO}=1: 1(0.2$ $\mathrm{MPa}$ ), $0.00096 \mathrm{mmol} \mathrm{Rh}$ with a molar ratio of $\mathrm{P} / \mathrm{Rh}=10, \mathrm{~S} / \mathrm{C}=2000,10$ h.

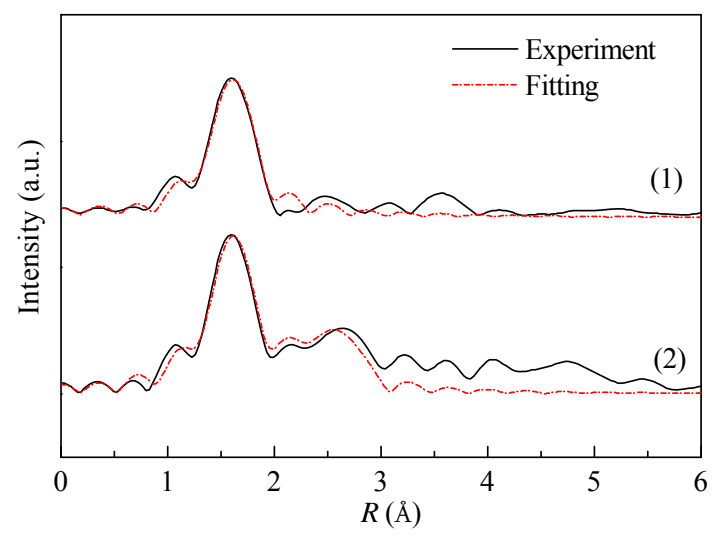

Fig. 3. The Rh K-edge $\mathrm{k}^{3}$-weighted Fourier transform spectra from EXAFS. (1) Fresh Rh/Poly-1; (2) Used Rh/Poly-1.

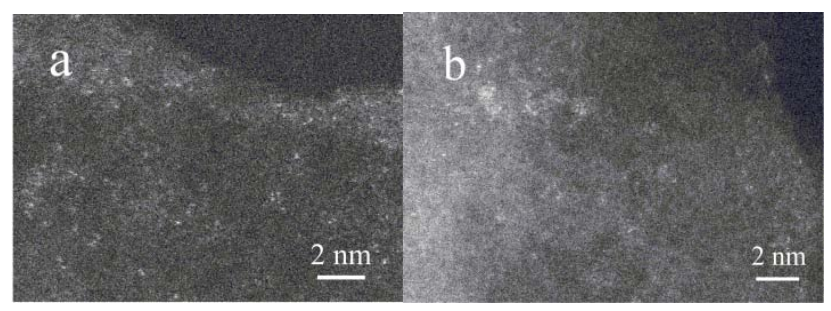

Fig. 4. High-angle annular dark-field scanning transmission electron microscopy (HAADF-STEM) images of the fresh Rh/Poly-1 (a) and used Rh/Poly-1 (b).

To confirm the coordination status of the Rh species in our heterogeneous catalyst, extended X-ray absorption fine structure spectroscopy (EXAFS) and high-angle annular dark-field scanning transmission electron microscopy (HAADF-STEM) characterization were employed for the fresh and used Rh/Poly-1 (Figs. 3 and 4). According to the curve-fitting results, in the fresh Rh/Poly-1 each Rh atom is coordinated with three $\mathrm{P}$ atoms (derived form BINAP) and two $\mathrm{O}$ atoms (derived from acetylacetone in the $\mathrm{Rh}(\mathrm{CO})_{2}$ (acac) precursor) (Table 4). More importantly, no $\mathrm{Rh}-\mathrm{Rh}$ bond can be detected in the fresh sample of Rh/Poly-1, which indicated that the Rh species were coordinated with chiral ligands and efficient molecular catalysts were afforded. This was further confirmed by the HAADFSTEM image (Fig. 4). After Rh/Poly-1 was used seven times, one $\mathrm{Rh}$ atom was coordinated with three $\mathrm{P}$ atoms, one $\mathrm{CO}$ molecule (Table 4) and one $\mathrm{H}$ atom. This result is in accordance with the mechanism of Rh-based homogeneous hydroformylation catalysis, in which the acetyl acetone molecule is replaced by the $\mathrm{CO}$ and $\mathrm{H}$ to form the active species for hydroformyla-

Table 4

The curve-fitting analysis of the EXAFS traces.

\begin{tabular}{lccccc}
\hline Rh/Poly-1 & Shell & $N$ & $R(\AA)$ & $\sigma^{2} \times 10^{3}$ & $R$ factor \\
\hline Fresh & Rh-P & 3.0 & 2.13 & 3.0 & 0.013 \\
\multirow{3}{*}{ Used } & Rh-O & 2.0 & 2.11 & 3.0 & \\
& Rh-P & 3.0 & 2.13 & 1.0 & 0.007 \\
& Rh-C & 1.0 & 1.69 & 4.9 & \\
& Rh-Rh & 1.5 & 2.83 & 3.0 & \\
\hline
\end{tabular}

$N$, coordination number; $R$, distance between absorber and backscatter; $\sigma^{2}$, Debye-Waller factor. 
tion $[7,8]$. These observations indicated that just like the homogeneous catalysis mechanism, it was reasonable to attribute the improvement of enantioselectivity in the case of Rh/Poly-1 catalyst to a favorable chiral pocket effect. In addition, only a few $\mathrm{Rh}-\mathrm{Rh}$ bonds were detected after the seventh run (Table 4). The content of Rh particles was very low according to the HAADF-STEM image, and the Rh particles had no obvious effect on the enantioselectivity during recycling (Fig. 4).

\section{Conclusions}

We successfully synthesized a new vinyl-functionalized chiral ligand $(S)-5,5^{\prime}$-divinyl-BINAP and its related chiral porous organic polymers. After impregnating with Rh species, the porous polymeric catalysts with chiral nanopockets were applied in the heterogeneous asymmetric hydroformylation of styrene. Encouragingly, the enantioselectivity of Rh/Poly-1 was 1.67 times higher than that of the homogeneous analogue. This enhancement of enantioselectivity could be attributed to the introduction of the flexible chiral nanopockets. Furthermore, with excellent activity and recyclability, the easily prepared BINAP-based chiral porous organic polymeric catalyst may have further applications in the industrial production of chiral aldehydes and other fine chemicals. Other efficient heterogeneous asymmetric catalytic systems for the production of fine chemicals are being developed in our laboratory.

\section{References}

[1] F. Agbossou, J. F. Carpentier, A. Mortreaux, Chem. Rev., 1995, 95, 2485-2506.

[2] A. Gual, C. Godard, C. Claver, S. Castillon, Eur. J. Org. Chem., 2009, 1191-1201.

[3] L. Rovira, M. Vaquero, A. Vidal-Ferran, J. Org. Chem., 2015, 80, 10397-1043.

[4] A. Gual, C. Godard, S. Castillon, C. Claver, Adv. Synth. Catal., 2010, 352, 463-477.

[5] M. Dieguez, O. Pamies, C. Claver, Chem. Commun., 2005, 1221-1223.
[6] N. Sakai, S. Mano, K. Nozaki, H. Takaya, J. Am. Chem. Soc., 1993, 115, 7033-7034.

[7] I. del Rio, W. G. J. de Lange, P. W. N. M. van Leeuwen, C. Claver, J. Chem. Soc., Dalton Trans., 2001, 1293-1300.

[8] M. Dieguez, M. M. Pereira, A. M. Masdeu-Bulto, C. Claver, J. C. Bayon, J. Mol. Catal. A, 1999, 143, 111-122.

[9] A. M. Masdeu-Bulto, A. Orejon, A. Castellanos, S. Castillon, C. Claver, Tetrahedron: Asymmetry, 1996, 7, 1829-1834.

[10] J. M. Brown, S. J. Cook, R. Khan, Tetrahedron, 1986, 42, 51055109.

[11] G. Consiglio, F. Morandini, M. Scalone, P. Pino, J. Organomet. Chem., 1985, 279, 193-202.

[12] S. Akutagawa, Appl. Catal. A, 1995, 128, 171-207.

[13] P. Y. Wang, X. Liu, J. Yang, Y. Yang, L. Zhang, Q. H. Yang, C. Li, J. Mater. Chem., 2009, 19, 8009-8014.

[14] J. Peng, X. F. Wang, X. M. Zhang, S. Y. Bai, Y. P. Zhao, C. Li, Q. H. Yang, Catal. Sci. Technol., 2015, 5, 666-672.

[15] M. Berthod, G. Mignani, G. Woodward, M. Lemaire, Chem. Rev., 2005, 105, 1801-1836.

[16] A. G. Hu, H. L. Ngo, W. B. Lin, Angew. Chem. Int. Ed., 2004, 43, 2501-2504.

[17] G. D. Liu, X. Q. Liu, Z. H. Cai, G. J. Jiao, G. Q. Xu, W. J. Tang, Angew. Chem., Int. Ed. 2013, 52, 4235-4238.

[18] G. A. Carriedo, F. J. Garcia Alonso, A. P. Soto, Macromolecules, 2006, 39, 4704-4709.

[19] J. L. G. Alvarez, M. E. Amato, G. M. Lombardo, G. A. Carriedo, F. Punzo, Eur. J. Inorg. Chem., 2010, 4483-4491.

[20] W. K. An, M. Y. Han, C. A. Wang, S. M. Yu, Y. Zhang, S. Bai, W. Wang, Chem. Eur. J., 2014, 20, 11019-11028.

[21] H. Q. Yang, J. Li, J. Yang, Z. M. Liu, Q. H. Yang, C. Li, Chem. Commun., 2007, 1086-1088.

[22] X. M. Zhang, Y. P. Zhao, J. Peng, Q. H. Yang, Green Chem., 2015, 17, 1899-1906.

[23] X. Wang, J. Li, S. M. Lu, Y. Liu, C. Li, Chin. J. Catal, 2015, 36, $1170-1174$.

[24] D. J. Bayston, J. L. Fraser, M. R. Ashton, A. D. Baxter, M. E. C. Polywka, E. Moses, J. Org. Chem., 1998, 63, 3137-3140.

[25] T. T. Adint, C. R. Landis, J. Am. Chem. Soc., 2014, 136, 7943-7953.

[26] R. P. Jumde, A. Di Pietro, A. Manariti, A. Mandoli, Chem. Asian J., 2015, 10, 397-404.

[27] H. B. Yu, Q. S. Hu, L. Pu, Tetrahedron Lett., 2000, 41, 1681-1685.

\section{Graphical Abstract}

Chin. J. Catal., 2017, 38: 691-698 doi: 10.1016/S1872-2067(17)62790-6

Porous Rh/BINAP polymers as efficient heterogeneous catalysts

for asymmetric hydroformylation of styrene: Enhanced enantioselectivity realized by flexible chiral nanopockets

Tao Wang, Wenlong Wang, Yuan Lyu *, Kai Xiong, Cunyao Li, Hao Zhang, Zhuangping Zhan, Zheng Jiang, Yunjie Ding *

Dalian Institute of Chemical Physics, Chines Academy of Sciences; University of Chinese Academy of Sciences; Xiamen University; Shanghai Institute of Applied Physics, Chines Academy of Sciences

A series of polymer-supported Rh catalysts were obtained through the copolymerization of $(S)-5,5^{\prime}$-divinyl-BINAP and other co-monomers. The heterogeneous catalyst exhibited higher enantioselectivity than the corresponding homogeneous complex owing to the presence of flexible chiral nanopockets.

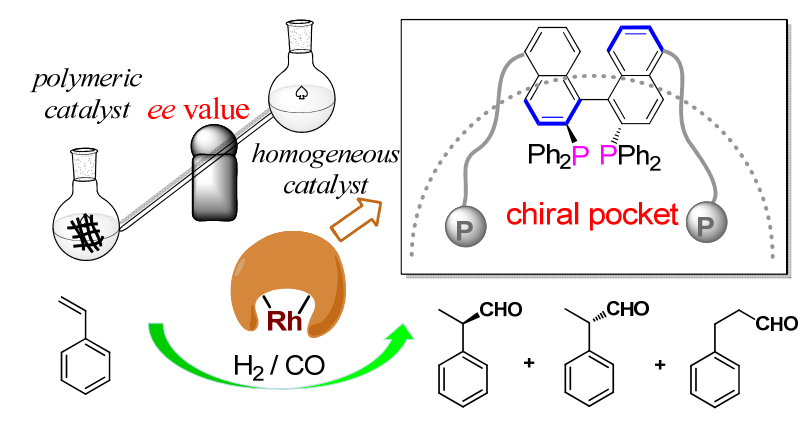


[28] T. Wang, Y. Lyu, X. K. Chen, C. Y. Li, M. Jiang, X. G. Song, Y. J. Ding, RSC Adv., 2016, 6, 28447-28450.

[29] F. Shibahara, K. Nozaki, T. Hiyama, J. Am. Chem. Soc., 2003, 125, 8555-8560.

[30] Q. Sun, Z. F. Dai, X. L. Liu, N. Sheng, F. Deng, X. J. Meng, F. S. Xiao, J. Am. Chem. Soc., 2015, 137, 5204-5209.

[31] C. Y. Li, K. Xiong, L. Yan, M. Jiang, X. G. Song, T. Wang, X. K. Chen, Z.
P. Zhan, Y. J. Ding, Catal. Sci. Technol., 2016, 6, 2143-2149.

[32] C. Y. Li, L. Yan, L. L. Lu, K. Xiong, W. L. Wang, M. Jiang, J. Liu, X. G. Song, Z. P. Zhan, Z. Jiang, Y. J. Ding, Green Chem., 2016, 18, 2995-3005.

[33] Q. Sun, X. J. Meng, X. Liu, X. M. Zhang, Y. Yang, Q. H. Yang, F. S. Xiao, Chem. Commun., 2012, 48, 10505-10507.

[34] Y. Takaya, M. Ogasawara, T. Hayashi, Chirality, 2000, 12, 469-471.

\title{
多孔有机含BINAP聚合物负载Rh催化剂在苯乙烯不对称氢甲酰化中的应用: 柔性手性口袋对产物对映体选择性的提高作用
}

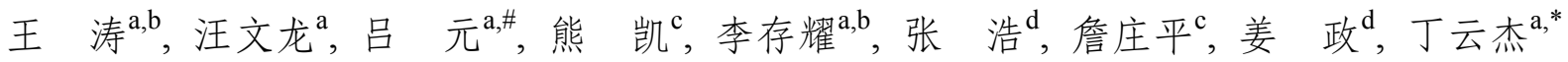 \\ ${ }^{\mathrm{a}}$ 中国科学院大连化学物理研究所洁净能源国家实验室(筹), 辽宁大连 116023 \\ 中国科学院大学, 北京 100049 \\ $\mathrm{c}^{\mathrm{r}}$ 厦门大学化学系, 福建厦门361005 \\ $\mathrm{d}$ 中国科学院上海应用物理研究所上海同步辐射中心, 上海 201204
}

摘要: 不对称氢甲酰化是合成具有单一光学活性物质(如光学活性的醛、 $\alpha$-氨基酸和醇等)最为重要的反应之一. 尽管不对 称氢甲酰化反应的研究超过 40 年, 但仍然是催化体系中具有挑战性的课题. 该反应涉及到产物的化学选择性、立体选择性 和对映体选择性的优化. 目前, 在Rh催化体系中, 使用磷-亚磷酸酯手性配体或双亚磷酸酷配体可以在不对称氢甲酰化反 应中取得优异的催化性能. 然而在 $\mathrm{Rh}$ /手性双膦配体催化体系中, 不对称氢甲酰化反应性能通常很低. 以BINAP配体为例, 负载 $\mathrm{Rh}$ 金属后, 在催化苯乙烯不对称氢甲酰化反应中, 产物的ee值只有 $25 \%$. 同时, 由于均相催化体系存在催化剂回收和产 物提纯等问题, 因此有必要研究多相不对称氢甲酰化反应催化剂.

本文使用乙烯基修饰的BINAP配体 5,5'-divinyl-BINAP 与具有不同结构的共聚单体二乙烯基苯或1,3,5-三乙烯基苯基 苯共聚, 得到具有不同孔结构的聚合物Poly-1和Poly-2. 为了比较, 利用线性共聚单体乙二醇二甲基丙烯酸甲酯与乙烯基 BINAP共聚得到聚合物Poly-3. 上述三种聚合物材料负载金属Rh后, 用作苯乙烯不对称氢甲酰化反应的催化剂.

固体 ${ }^{13} \mathrm{C}$ 核磁分析表明, 三种聚合物材料负载金属后仍然保持较为稳定的 $\mathrm{C}$ 骨架结构. 通过 ${ }^{31} \mathrm{P}$ 核磁可以看到, 嵌入在材 料骨架中的BIANP仍然保持未被氧化的状态. $\mathrm{N}_{2}$ 物理吸附结果发现Poly-1和Poly-2 具有较大的比表面积和孔体积, 而 Poly-3的比表面积最小. 热重分析显示, 这些材料具有较高的热稳定性.

在不同反应溶剂中催化剂活性差异较大. 通过优化反应温度和合成气压力后, 催化剂 Rh/Poly 1 在 $80{ }^{\circ} \mathrm{C}$ 和 $0.2 \mathrm{MPa}$ 下产 物的对映体选择性可高达 $58.9 \%$, 支链醛与直链醛的比值为 8.5 ; 而在相同反应条件下, 均相催化剂Rh-BINAP的 $e e$ 值仅为 $35.3 \%$, 但高于 Rh/Poly-3. 这是由于三个多相催化剂骨架中BINAP周围环境不同所致. 前两个催化剂中, BINAP与空间位阻 较大的单体相连接, 使得反应底物按照特定方向与催化活性位点接触, 形成了类似于手性口袋的结构. 而Rh/Poly- 3 中, BIANP周围是线性的共聚单体, 不能形成有效的手性口袋结构. Rh/Poly-1重复使用7次后, 催化活性没有显著下降. 拓展 $\mathrm{X}$ 射线吸收精细结构表征结果表明, $\mathrm{Rh} / \mathrm{Poly}-1$ 催化剂使用前没有 $\mathrm{Rh}-\mathrm{Rh}$ 键存在, 但经重复使用后, $\mathrm{Rh}$ 金属部分聚集, 生成了 $\mathrm{Rh}-\mathrm{Rh}$ 键. 球差电镜照片也证实了这一点.

关键词: 多孔有机聚合物; 多相催化; 不对称氢甲酰化; 手性提高; 手性口袋

收稿日期: 2016-12-15. 接受日期: 2017-01-15. 出版日期: 2017-04-05.

*通讯联系人. 电话: (0411)84379143; 传真: (0411)84379143; 电子信箱: dyj@dicp.ac.cn

\#通讯联系人. 电话: (0411)84379601; 传真: (0411)84379143; 电子信箱: luyuan@dicp.ac.cn

基金来源: 中国科学院战略性先导科技专项(XDB17020400).

本文的英文电子版由Elsevier出版社在ScienceDirect上出版(http://www.sciencedirect.com/science/journal/18722067). 